\title{
Energy Saving Policy and Integrated Urban Planning for the Future
}

\author{
Mohammad Reza Sadeghi Moghaddam ${ }^{1, *}$, Fattaneh Hajinorouzi ${ }^{2}$, Mojtaba Shirazkian ${ }^{1}$, \\ Salameh Azimi ${ }^{3}$ \\ ${ }^{1}$ Department of urban planning, Qazvin Branch, Islamic Azad University, Qazvin, Iran \\ ${ }^{2}$ Department of Architecture, and urban planning Islamic Azad University, Qazvin Branch, Qazvin, Iran \\ ${ }^{3}$ Faculty of Industrial and Mechanical Engineering, Qazvin Branch, Islamic Azad University, Qazvin, Iran \\ *Corresponding Author: m.sadeghi62@gmail.com
}

Copyright $@ 2014$ Horizon Research Publishing All rights reserved.

\begin{abstract}
The attention to sustainable urban development, participated urban planning, the consideration of territory as nonrenewable resource, sustainable mobility and so on has been characterizing also the investigation in the field of urban and regional sciences. This paper focuses on the crucial role for sustainable energy planning in creating the context and conditions for integrating and optimizing clean and efficient energy use within the urban built environment. The paper seeks to codify a new process of sustainable town planning which is able to indicate the real actions to operate on the city. The paper is divided into three parts. The first part expresses some definitions that were extracted from various projects. The second part explains and describes The Process of Energy Planning. Finally, strategic policies and actions are proposed for urban planning that can help to reach energy saving and Sustainable Energy Planning.
\end{abstract}

Keywords Energy Saving, Urban Planning, Policies, Sustainable Energy Planning

\section{Introduction}

Cities are centers of high population density and energy consumption throughout the world, While occupying just 2\% of the land, they account for approximately $75 \%$ of the world's energy usage, and contribute to $80 \%$ of global greenhouse gas emission Global climate control has recently emerged as an important international issue and among terrestrial ecosystems urban areas play an important Global trends, including our growing concerns about climate change, energy security and the adverse impacts of rapid urbanization, are providing substantial "market push" for energy efficiency and renewable energy to support sustainable development.

As developing countries to become industrialized and urbanized, heavy metal pollution is likely to reach disturbing levels [1]. These socio-economic and environmental developments are especially challenging cities, where over half of the world's population resides, to increase the efficiency, reliability and sustainability of their energy use through innovative infrastructure solutions and new governance approaches and it is well known that environmental pollution is a product of urbanization and technology and other attendant factors of pollution density, industrialization and mechanization that serve to provide the necessities of the population [1]. Due to their population densities, industrial and commercial activity, and complex energy systems, our cities can become drivers for a new clean energy future.

\section{Concept and Aims}

Energy planning at a town and city scale needs a strategic approach, supported by strong planning policies and complementary enabling mechanisms.

Energy strategies should be driven by a common purpose to reduce $\mathrm{CO}_{2}$ emissions and increase the energy security of communities, and should be based on a clear and rational relationship between:

- The benefits of low carbon energy generation technologies

Access to renewable resources in the local environment

- The forms and grades of energy required for different end-uses

- Parameters for cost effective and efficient deployment

- The scale and form of development opportunities [2]

\subsection{This Study Has Been Done for the Following Reasons}

- Environmental protection as a key element of the 
urban planning philosophy;

- Changing local regulations in favor of an environmentally compatible energy policy;

- Establishment of new energy standards for old as well as new buildings;

- Implementation of a pilot housing project in order to gain experience;

- Promotion of solar energy installations;

- Integration of an environmentally compatible energy policy into a comprehensive urban environmental strategy.

- The aspects of energy usage have been integrated into different planning processes;

- Since urban transport energy consumption is one of the greatest challenge in an urban policies which has a crucial impact on long term energy consumption.

\subsection{Defining Sustainable Urban Energy Planning}

Sustainable urban energy planning integrates sustainable energy ${ }^{1}[3,4]$, clean energy technologies ${ }^{2}[5,6]$ and responsible resources management strategies for the development of economically, socially and environmentally healthy communities. The ultimate aim is to bring about a paradigm shift with respect to energy and resource use within all of the functions of a community and to change infrastructure parameters and development patterns by affecting "how and where we build" and "how we generate, deliver and use energy." Sustainable energy planning seeks to strike a new balance in the dynamics between energy and resource supply and demand, by fusing energy and resource efficiency with "smart growth," "smart grid," intelligent transportation system management" and similar urban strategies within the following framework of community planning and design principles ${ }^{3}$ :

\subsubsection{Sustainable Usage of Energy Resources}

Planning and design should maximize the efficient use of energy resources across all end uses, while minimizing direct and indirect adverse impacts on the environment.

\subsubsection{Ecological Community Form and Function}

Planning and design should emulate nature to maximize the benefit of natural systems and preserve and restore the natural environment. Urban functions should be managed to reinforce natural flows and characteristics, creating a balance

1 "Sustainable energy" is energy saved through efficient end-use practices or derived from non-depleting "renewable" energy resources such as solar, wind, biomass, geothermal and low-impact hydroelectricity.

2 "Clean energy technologies" refers to those energy supply or end-use technologies that, compared with conventional technologies currently in commercial use, emit substantially lower levels of GHG and air criteria pollutants over their life cycle and generate substantially smaller or less-toxic volumes of solid, liquid or gaseous wastes. Clean energy technologies include those that allow the production, transport, storage and use of fossil energy resources with relatively high efficiency and relatively low impact on the environment.

3 "Planning \& Design Guidelines for Energy-Efficient Community Development," D. Newman, Gas Technology Institute (2004) at 4-5; GTI Model Design at 15-16. and mutually supportive cycle of interaction between built and natural environments.

\subsubsection{Environmentally Sound and Energy Efficient Land Use Optimization:}

Planning and design should seek to minimize the consumption of energy, material and natural resources by restructuring and more efficiently utilizing the existing urban footprint. In addition, compact, mixed-use development, along with the co-location of compatible uses and increasing proximate loads, can enable cost-effective distributed energy resource applications and urban mass transit systems.

\subsubsection{Energy and Environmental}

Technology Integration: Planning and design should integrate cleaner energy systems into development projects, using "whole building" and "community-scale" approaches to maximize energy performance and economic value, while minimizing adverse environmental impacts. Efforts should capitalize upon technology advancements, but promote integrated technical systems needed to expand the use of local renewable and recyclable energy resources, build sustainable local and regional energy networks, secure underground distribution systems for critical urban facilities, develop supply and demand network control systems, and establish more technology-ready infrastructure.

\subsubsection{Community Resources Management}

Wherever possible, planning and design should engage community residents in the efficient use of energy and material resources by decentralizing resource management systems to the neighborhood level. Neighborhood-based systems should be designed to provide ongoing systemic management of community resources and promote shared energy resources and material and process efficiencies, based on town energy management plans.

\subsubsection{Social Equity and Economic Vitality}

Energy-efficient planning and design should increase access to affordable housing, public services and employment for lower-income populations and stimulate local economic opportunities.

\subsection{What is a Strategic Energy Plan?}

A strategic energy plan is a roadmap to achieving community energy goals in both the near and long term. The goals are determined by stakeholder input, so the plans are inherently local and have stakeholder buy-in, leading to a greater likelihood of success of the plan over time. A strategic energy plan can be part of a greenhouse gas emission plan, a greening plan, or a community master plan $[7,8]$

\subsection{What are the Benefits of Strategic Energy Planning?}

Energy planning has several different advantages such as: 
Cost savings and increased comfort for consumers, Delayed or cancelled infrastructure development for the community and reduced climate change impact from the community, as it discussed we can conclude that strategic energy planning is so applicable for buildings and their structures.

\subsection{Building Energy Simulation Tools and Their Applications}

Building energy simulations are conducted by design professionals (architects, engineers and energy consultants etc.) using building design and energy analysis software tools to analyze the energy performance of their designs [9]. A database developed by the U.S. Department of Energy (DoE) currently lists almost four hundred energy tools designed to simulate the energy performance of buildings and/or their components [10]. Many of these building simulation tools are designed to be used during different phases of the building design lifecycle and have different functionalities.

\subsection{Building Energy Benefits}

Buildings account for around half of primary energy consumption, hence $\mathrm{CO}_{2}$ emissions, in the $\mathrm{UK}$ and other developed countries. A large proportion of this energy is used to maintain internal building temperatures through heating and cooling systems. This section of the report will therefore address the potential building energy reduction benefits arising from the enhanced thermal properties of a green roof [11].

Some useful and practical policies which could be applied in urban infrastructures are:

\section{Result and discussion}

\subsection{Energy Conscious Housing Policy}

The following energy saving measures was included in the dwellings which have an average volume of 200 cubic meters:

Use of passive solar energy. The houses are oriented to the south with large windows directed to the south and small windows to the north;

Use of natural cooling systems. Cellar-like cupboards were constructed in the north facing-walls for food conservation without using fossil energy;

Use of window insulation. Shutters on the outside of windows provide better insulation and can be closed when appropriate. These shutters can be operated from inside;

Use of buffers. Porches are placed at front and back doors in order to prevent cold air from entering the house;

Use of insulated glass. The windows contain triple glazing or double glazing with a special foil over the glass;

Draught prevention, by means of sealing possible crevices and providing doors and windows with three hinges instead of the usual two;

Use of economized ventilation systems. A balanced ventilation mechanism captures the warm air leaving the house by means of a heat exchanger;

Use of efficient water boilers. A high efficiency boiler with electronic display provides heated water for direct use in kitchen and bathroom which passes through radiator pipes for room heating.

The thermal insulation of houses above the national standards incorporated the following energy saving methods:

- Installation of double glazing;

- Insulation of exterior walls;

- Replacing old wooden window frames with synthetic ones to seal off cracks and crevices;

- Replacing the conventional heating system with high efficiency central heating systems. The tenants had the choice of an individual central heating system or the connection to a local communal heating system.

\subsection{Traffic Policy}

In new built areas traffic planning includes the designing of the entire public space as a pedestrian zone. There is no division between roads and footpaths. Nevertheless, cars have access to the area and there are also a certain number of car parks. However, some areas consist of speed-reducing obstacles at a maximum distance of 50 meters and at night there is sufficient lighting to recognize the facilities. The policy is mainly implemented to discourage through traffic and to promote environmentally friendly means of transport like walking and cycling. Separate tracks for bicycles are being constructed. All means of transportation have equal status. In addition, the municipalities developed the new built area together with the public transport system. After the completion of the first 200 houses a bus route went into operation. The tramway connection was opened before the first thousand houses had been built.

Energy consumption by urban transport is a particular reason for concern for several reasons. First of all, it already represents a large share of the urban energy balance, generally equivalent to the residential share, which is between $20 \%$ and $50 \%$ of total urban energy consumption (excluding industry).

Furthermore, the trends scenarios forecast that it is this consumption that will experience the highest growth. Experts agree on a current trends scenario in which urban mobility based on individual motorized modes of transport experiences a boom. Finally, analyzing the factors determining urban transport energy consumption is extremely complex and these factors are less easily influenced by public policies. Moreover, urban spatial structures, whose influence on the demand for transport and therefore on transport energy consumption is easy to understand, have a lifetime and resilience far greater than 
those of buildings. Urgent action is required on this score and action now will condition the future for a very long time.

\subsection{Green Buildings and Green Practices with}

1. Improve indoor air quality

2. Improve water efficiency

3. Promote energy efficiency and conservation

4. Establish solid waste management practices

5. Advance eco-friendly site development

6. Further the utilization of green materials in all phases of the building construction.

\subsection{Shifts to Energy Efficient Lights Program}

1. Replacement of all incandescent lights with energy efficient lights (EELs) in city government owned buildings and facilities

2. Replacement of all incandescent lights with energy efficient lights (EELs) in public markets

- Conservation Measures on Public Facilities

- Managed by the City's Engineering Department under the Task Force Building Facilities and Equipment Maintenance

- Reduction of operation by one (1) hour on air-conditioning units

- Turning-off of lights during lunch breaks

- Reduction in the number of lights/bulbs turned on

\subsection{Sustainable Transportation}

- Component of the Climate Friendly Cities Program

- Envisions the utilization of electric engine a means of public transportation

- Delve on waste conversion, electricity production and fuel switching for transport

- Utilization of biofuels encouraged in the City.

\subsection{Further Supporting Activities in Urban Development}

A planting and maintenance program was put in to practice which mainly focused on the planting of new trees and the removal of hard surface (asphalt, bricks, paving materials) as far as possible.

- Reduced energy consumption and peak load demand;

- Deferred transmission and distribution expansions or upgrades;

- Increased utilization of existing utility infrastructure;

- Reduced electricity costs;

- Improved power quality and reliability;

- Increased gray water use and recovery;

- Reduced environmental impacts, including air and greenhouse gas emissions;

- Reduced risks in adopting energy efficient and renewable energy technologies;
- Reduced fuel demand and resulting emissions;

- Enhanced asset value and land use;

- Load following and dispatching capabilities;

- Reduced capital and operating costs for RE deployment;

- New value-added products and services; and

- Innovative transport and mobility strategies.

\subsection{Energy saving retrofit}

The recognition of the need for carbon reduction from the built environment, along with EU directives, more stringent building regulations and general environmental concerns has lead a number of researchers to develop general lifecycle design frameworks for buildings to support energy efficient building design. However as mentioned earlier, the approaches adopted often demand that architects and building contractors completely transform current building design practice.

\section{Case Study}

The case study of our project is 25 apartments on Ferdowsi Street, Qazvin, Iran. Our group, first interviewed those apartment's inhabitants, then give them some important and applicable recommendations for saving energy. The inhabitants were asked by these questions by our group members which persuade them for energy saving.

- How much money do you spend on energy?

- Where are your greatest energy losses?

- How long will it take for an investment in energy efficiency to pay for itself in energy cost savings?

- Do the energy-saving measures provide additional benefits that are important to you-for example, increased comfort from installing double-paned, efficient windows?

- How long do you plan to own your current home?

- Can you do the job yourself or do you need a contractor?

- What is your budget?

- How much time do you have for maintenance and repairs?

Planning smart purchases and home improvements will maximize your energy efficiency and save you the most money. A more advanced alternative to performing a DIY energy assessment is to get advice from your state energy office, utility, or an independent energy auditor. A professional energy auditor uses special test equipment to find air leaks, areas lacking insulation, and malfunctioning equipment. The auditor analyzes how well your home's energy systems work together, and compares the analysis to your utility bills. After gathering information about your home, the auditor will recommend cost-effective energy improvements that enhance comfort and safety. Some will also estimate how soon your investment in efficiency upgrades will pay off. 
Four months later, only 18 inhabitants of those apartments were followed our recommendations, they repaired some of broken doors and windows, some of them were replaced those doors and windows by isolated one or double-paned, efficient windows. Some of them were isolated their doors and windows by covering them by plastics and some of them purchases the smart heaters (which is stop heating when the temperature is reached to $21^{\circ} \mathrm{C}$ ). Overall their energy saving was about 38 percents, by applying simple, easy and inexpensive ways for saving energy. The results are shown in table 1 . The results present since, using the smart heaters and double-paned, efficient windows are so inexpensive, they have the most efficient for saving energy.

Table 1. Some saving policies which were applied for 18 apartments

\begin{tabular}{|c|c|c|}
\hline Inhabitants & Saving policy & $\begin{array}{c}\text { Saving energy } \\
\text { policy(percentage) }\end{array}$ \\
\hline 8 & Smart heaters & 14 \\
\hline 2 & $\begin{array}{c}\text { Repairing broken doors } \\
\text { and windows }\end{array}$ & 8 \\
\hline 5 & $\begin{array}{c}\text { Installing the isolated } \\
\text { doors and windows }\end{array}$ & 12 \\
\hline 3 & Covering by plastics & 4 \\
\hline
\end{tabular}

\section{Conclusion}

This study has analyzed different important aspects of energy planning and the influencing factors of energy-saving behavior were also examined to obtain deep insights in to how to guide and stimulate the public to adopt energy-saving behavior. Some valuable and different recommendations were presented for governments and organizations.

\section{REFERENCES}

[1] S. Azimi, M. Sadeghi Moghaddam, Effect of Mercury Pollution on the Urban Environment and Human Health, Environment and Ecology Research 1(1): 12-20, 2013.

[2] N. Dodd, Community Energy, urban planning for a low carbon future, 6, 2008.

[3] A. H Ghaffarian Hoseini a,n, Nur Dalilah Dahlan, U. Berardi, A.Ghaffarian Hoseini, N.Makaremi a, M. Ghaffarian Hoseini, Sustainable energy performances of green buildings: A review of current theories, implementations and challenges, RenewableandSustainableEnergyReviews25, 1-17, 2013.

[4] B. Sadownik, M. Jaccard, Sustainable energy and urban form in China: the relevance of community energy management, Energy Policy 29, 55-65, 2001.

[5] L. Olmos a,b,n, SophiaRuester ,S.JenLiong, On the selection of financing instruments to push the development of new technologies: Application to clean energy technologies, Energy Policy 43, 252-266, 2012.

[6] H, Liu, N. DapengLiang, A review of clean energy innovation and technology transfer in China, Renewable and Sustainable Energy Reviews 18, 486-498, 2013.

[7] US. Department of Energy, 2009.

[8] P.Jacobs, H.Henderson. State-of-the-art review whole building, building envelope, and HVAC component and system simulation and design tools. Architectural Energy Corporation, 2002.

[9] S. Dawood, T. Crosbie, N.Dawood, R. Lord, Designing low carbon buildings: A framework to reduce energy consumption and embed the use of renewables, Sustainable Cities and Society 8,63-71, 2013.

[10] H.F. Castletona,*, V. Stovinb, S.B.M. Beckc, J.B. Davison, Green roofs; building energy savings and the potential for retrofit,Energy and Buildings 42, 2010.

[11] Cynthia Rosenzweig, Stuart Gaffin, and Lily Parshall, Green Roofs in the New York Metropolitan Region, Columbia University Center for Climate Systems Research NASA Goddard Institute for Space Studies,http://ccsr.columbia.edu/cig/greenroofs. 